\title{
Development and optimisation of stochastic targeted (STAR) glycaemic control for neonatal intensive care
}

\author{
Jennifer L. Dickson*,Aaron J. Le Compte*, Richard P Floyd, J. Geoffrey Chase*, Adrienne Lynn**, Geoffrey M. \\ Shaw***
}

* Department of Mechanical Engineering, University of Canterbury, Christchurch, New Zealand

** Neonatal Department, Christchurch Women's Hospital, Christchurch, New Zealand

*** Department of Intensive Care, Christchurch Hospital, Christchurch, New Zealand

\begin{abstract}
Hyperglycaemia is a common complication of prematurity and stress in neonatal intensive care units (NICUs). It has been linked to worsened outcomes and mortality. There is currently no universally accepted best practice glycaemic control method, with many protocols lacking patient specificity and relying heavily on clinical judgment. The result is persistent hypoglycaemia and poor control. This research presents the virtual trial design and optimisation of a stochastic targeted (STAR) approach to improve performance and reduce hypoglycaemia. Clinically validated virtual trials based on NICU patient data ( $\mathrm{N}=61$ patients, 7006 hours) are used to develop and optimise a STAR protocol that improves on current STAR-NICU performance and reduce hypoglycaemia. Five approaches are used to maximize the stochastic range of BG outcomes within $4.0-8.0 \mathrm{mmol} / \mathrm{L}$, and are designed based on an overall cohort risk to provide clinically specified risk (5\%) of BG above or below a clinically specified level. The best protocol placed the $5^{\text {th }}$ percentile BG outcome for an intervention on $4.0 \mathrm{mmol} / \mathrm{L}$ band. The optimised protocol increased \%BG in the $4.0-8.0 \mathrm{mmol} / \mathrm{L}$ band by $7 \%$ and the incidence of BG $<2.6 \mathrm{mmol} / \mathrm{L}$ by 1 patient (50\%). Significant intra- and inter- patient variability reduced possible performance gains, indicating a need for patient-specific or sub-cohort specific approaches to manage variability.
\end{abstract}

Keywords: Insulin sensitivity, control algorithms, physiological models, simulation, intensive care

\section{INTRODUCTION}

Hyperglycaemia is a common complication of prematurity in the neonatal intensive care unit (NICU) resulting from underdeveloped glucose regulation systems and a hormonebased stress response (Barker and Rutter, 1996). It has been linked to worsened outcomes and mortality (Hays et al., 2006, Heimann et al., 2007), increased ventilator dependence and clinical length of stay (Alaedeen et al., 2006), and other complications (Alaedeen et al., 2006, Hays et al., 2006). Hypoglycaemia in this cohort is also linked to adverse outcomes and death (Lucas et al., 1988).

There is currently no best practice method or target for glycaemic control in pre-term infants. Blood glucose (BG) levels are often controlled by varying nutritional input, which may not be ideal for infant growth (Thabet et al., 2003). To date, fixed or ad hoc protocols are often utilised, which lack patient specificity and rely extensively on clinical judgement. Hence, the few larger trials have experienced problems with persistent hypoglycaemia and poor control (Beardsall et al., 2008). However, using insulin to treat hyperglycaemia has been associated with positive outcomes (Beardsall et al., 2008, Binder et al., 1989, Collins et al., 1991, Kanarek et al., 1991, Thabet et al., 2003).

Model-based control has shown benefit in the NICU and adult ICU. These methods titrate care by identifying patientspecific insulin sensitivity over time. In contrast, fixed protocols assume constant insulin sensitivity across all patients, and weight-based protocols assume a patientspecific insulin sensitivity that remains constant over the entire treatment period (Le Compte et al., 2011). Neither assumption is accurate, resulting in poor control and excessive hypoglycaemia (Le Compte et al., 2010b).

Stochastic TARgeting (STAR) is a model-based accurate glycaemic control (AGC) framework that directly quantifies inter- and intra- patient variability by forecasting a range of possible BG outcomes based on current patient-specific metabolic state ( Le Compte et al., 2010b). It overlaps this range with a $\mathrm{BG}$ target band to maximise safety and the likelihood of BG in band. This research presents the virtual trial design optimisation of a STAR-NICU control approach. The goals are to reduce hypoglycaemia and improve performance of an existing clinically applied NICU controller (Le Compte et al., 2009).

\section{METHODS}

Optimisation of the STAR approach for the NICU used clinically validated virtual trial methods (Chase et al., 2010) and virtual patients created from NICU clinical data.

\subsection{System model}

A clinically validated Neonatal Intensive Care InsulinNutrition-Glucose (NICING) metabolic model is used (Le Compte et al., 2010a): 


$$
\begin{gathered}
\dot{G}=-p_{G} G(t)-S_{I} G(t) \frac{Q(t)}{1+\alpha_{G} Q(t)} \\
+\frac{P(t)+E G P * m_{\text {body }}-C N S * m_{\text {brain }}}{V_{g, f r a c}(t) * m_{\text {body }}} \\
\dot{I}=-\frac{n_{L} I(t)}{1+\alpha_{I} I(t)}-n_{K} I(t)-n_{I}(I(t)-Q(t)) \\
+\frac{u_{e x}(t)}{V_{I, f r a c} * m_{\text {body }}} \\
+\left(1-x_{L}\right) \frac{u_{e n}(G)}{V_{I, f r a c} * m_{\text {body }}} \\
\dot{Q}=n_{I}(I(t)-Q(t))-n_{C} \frac{Q(t)}{1+\alpha_{G} Q(t)} \\
\dot{P}_{1}=-d_{1} P_{1}+P(t) \\
\dot{P}_{2}=-\min \left(d_{2} P_{2}, P_{\max }\right)+d_{1} P_{1} \\
P(t)=\min _{2}\left(d_{2} P_{2}, P_{\max }\right)+P N(t) \\
u_{e n}=\mathrm{I}_{\mathrm{B}} e^{\frac{-k_{I} u_{e x}}{V_{I}}}
\end{gathered}
$$

Insulin sensitivity $\left(S_{I}\right)$ is identified hourly and describes patient-specific time-varying metabolic state (Le Compte et al., 2011), enabling patient-specific control. Table 1 defines the other parameters. Notably, no saturation is applied for neonates (in Equation (1) $\propto_{G}=0$ ) (Farrag et al., 1997) .

\subsection{Control Protocol Optimisation}

\subsubsection{Stochastic Targeted Control}

As shown in Figure 1 STAR utilises the current identified $S_{I}$ to describe the current metabolic state of the neonate. A stochastic forecasting model ( Le Compte et al., 2010b) then predicts the range of possible changes in $S_{I}$ over the coming intervention interval. From this range of $S_{I}$ values a range of resulting BG outcomes can be calculated for a given insulin intervention. The aim is to overlap these predicted BG outcomes with a clinically specified target range to maximise the likelihood of the BG levels in that range. In this study, measurement intervals of 4 hours were chosen, due to restrictions arising from the very low blood volume of premature neonates.

\subsubsection{Protocol Optimisation}

The existing STAR NICU controller (Le Compte et al., 2009) checks insulin doses until the $50^{\text {th }}$ percentile BG prediction is $6.0 \mathrm{mmol} / \mathrm{L}$ (Le Compte et al., 2011). It then checks that $95 \%$ of predicted BG levels $\geq 4.0 \mathrm{mmol} / \mathrm{L}$, and reduces insulin if required. To improve this approach, the following control approaches were tested:

- PROTOCOL 1: Select insulin infusion rate that causes the $5^{\text {th }}$ percentile BG prediction to be within a tolerance of a clinically specified lower BG limit. As with the

\begin{tabular}{|c|c|c|}
\hline Variable & Description & Values \\
\hline$G$ & Blood glucose level & $(\mathrm{mmol} / \mathrm{L})$ \\
\hline$I$ & Plasma insulin concentration & $(\mathrm{mU} / \mathrm{L})$ \\
\hline$Q$ & $\begin{array}{l}\text { Interstitial insulin } \\
\text { concentration }\end{array}$ & $(\mathrm{mU} / \mathrm{L})$ \\
\hline$p_{G}$ & $\begin{array}{l}\text { Endogenous glucose } \\
\text { clearance }\end{array}$ & $0.0030\left(\mathrm{~min}^{-1}\right)$ \\
\hline$\alpha_{G}$ & $\begin{array}{l}\text { Saturation parameter for } \\
\text { insulin mediated glucose } \\
\text { removal }\end{array}$ & $0(\mathrm{~L} / \mathrm{mU})$ \\
\hline$\alpha_{I}$ & $\begin{array}{l}\text { Saturation parameter for } \\
\text { plasma insulin clearance }\end{array}$ & $0.0017(\mathrm{~L} / \mathrm{mU})$ \\
\hline$S_{I}$ & Insulin sensitivity & $(\mathrm{L} / \mathrm{mU} / \mathrm{min})$ \\
\hline EGP & $\begin{array}{l}\text { Endogenous glucose } \\
\text { production }\end{array}$ & $\begin{array}{c}0.0284 \\
(\mathrm{mmol} / \mathrm{min})\end{array}$ \\
\hline CNS & $\begin{array}{l}\text { Central nervous system } \\
\text { glucose uptake }\end{array}$ & $\begin{array}{c}0.088 \\
(\mathrm{mmol} / \mathrm{min})\end{array}$ \\
\hline$P(t)$ & $\begin{array}{l}\text { Glucose appearance in plasma } \\
\text { from dextrose intake }\end{array}$ & $(\mathrm{mmol} / \mathrm{min})$ \\
\hline$P N$ & Parenteral Nutrition & (mmol/min) \\
\hline$P_{\max }$ & $\begin{array}{l}\text { Maximal glucose flux from } \\
\text { gut to plasma }\end{array}$ & $\begin{array}{c}6.11 \\
(\mathrm{mmol} / \mathrm{min})\end{array}$ \\
\hline P1 & Glucose level in stomach & $(\mathrm{mmol})$ \\
\hline$P 2$ & Glucose level in gut & $(\mathrm{mmol})$ \\
\hline$V_{G}$ & $\begin{array}{l}\text { Plasma glucose distribution } \\
\text { volume }\end{array}$ & $0.5961(\mathrm{~L})$ \\
\hline$k_{I}$ & $\begin{array}{l}\text { Interstitial insulin transport } \\
\text { rate }\end{array}$ & $0.1\left(\min ^{-1}\right)$ \\
\hline$I_{B}$ & $\begin{array}{l}\text { Endogenous insulin } \\
\text { production }\end{array}$ & $15[\mathrm{mU} / \mathrm{L} / \mathrm{min}]$ \\
\hline$n_{I}$ & $\begin{array}{l}\text { Rate of transport between } \\
\text { plasma and interstitial insulin } \\
\text { compartments }\end{array}$ & $0.003\left(\mathrm{~min}^{-1}\right)$ \\
\hline$n_{K}$ & Renal insulin clearance & $0.150\left(\min ^{-1}\right)$ \\
\hline$n_{L}$ & Hepatic insulin clearance & $1\left(\min ^{-1}\right)$ \\
\hline$n_{C}$ & Interstitial insulin degradation & $0.003\left(\mathrm{~min}^{-1}\right)$ \\
\hline$x_{L}$ & $\begin{array}{l}\text { First-pass hepatic insulin } \\
\text { clearance }\end{array}$ & 0.67 \\
\hline$u_{e x}(t)$ & Exogenous insulin & $(\mathrm{mU} / \mathrm{min})$ \\
\hline$u_{e n}(t)$ & $\begin{array}{l}\text { Endogenous insulin } \\
\text { production }\end{array}$ & (mU/min) \\
\hline$V_{I}$ & $\begin{array}{l}\text { Plasma insulin distribution } \\
\text { volume }\end{array}$ & $0.0450(\mathrm{~L})$ \\
\hline$d_{1}$ & $\begin{array}{l}\text { Glucose absorption rate from } \\
\text { stomach }\end{array}$ & $0.0347\left(\mathrm{~min}^{-1}\right)$ \\
\hline$d_{2}$ & $\begin{array}{l}\text { Glucose absorption rate from } \\
\text { gut }\end{array}$ & $0.0069\left(\min ^{-1}\right)$ \\
\hline$D(t)$ & Dextrose intake & $(\mathrm{mmol} / \mathrm{min})$ \\
\hline $\boldsymbol{m}_{\text {body }}$ & Body mass & $(\mathrm{kg})$ \\
\hline$m_{\text {brain }}$ & Brain mass $\left(14 \% \boldsymbol{m}_{\text {body }}\right)$ & $(\mathrm{kg})$ \\
\hline
\end{tabular}
current protocol, this limits the risk of BG less than this lower target to 5\%, but does not target the median result.

- PROTOCOL 2: Select the insulin infusion rate placing the $95^{\text {th }}$ percentile BG prediction within a tolerance of an upper BG limit. This approach is more aggressive and does not consider a lower limit.

- PROTOCOL 3: As per Protocol 1 to give a total recommended insulin volume for the measurement
Table 1: Glucose-insulin metabolic model variable definition

interval (4 hours). Then give half of the insulin as a bolus for the first hour, and give the rest over the remaining 3 hours as an infusion.

- PROTOCOL 4: As per Protocol 1, but giving an insulin bolus that yields a $5^{\text {th }}$ percentile BG on $4.0 \mathrm{mmol} / \mathrm{L}$ in the first hour, followed by an infusion for the remaining 
time period so that the $5^{\text {th }}$ percentile BG remains on 4.0 $\mathrm{mmol} / \mathrm{L}$ at the end of the entire measurement interval .

- PROTOCOL 5: As per Protocol 4, but giving an insulin infusion, instead of a bolus, over the first hour.

Protocols 3, 4 and 5 allow more aggressive control where certainty is the greatest - in the first hour, immediately after $S_{I}$ is identified. In all protocols, if $\mathrm{BG}<4.0 \mathrm{mmol} / \mathrm{L}$ no insulin is given to for safety. An upper limit is applied to the amount the insulin rate can increase between treatments to ensure control is not compromised by glucose meter error, or short perturbations from the neonate's normal glycaemic state. No attempt was made to regulate nutritional inputs, which were left to clinical choice.

To improve the best protocol a sensitivity analysis was carried out on the limit on the increase in insulin rate between treatments. Limits on the rate of insulin change can limit control over-response to short-term changes in observed sensitivity to insulin caused by measurement device error or rapid fluctuations in patient condition. The limit used by the STAR-NICU controller is set to a maximum $0.03 \mathrm{U} / \mathrm{kg} / \mathrm{hr}$ increase in insulin infusion. The effect of higher and lower limits was investigated, as well as variable BG defined limits.

\subsection{Virtual Patient Data}

The virtual cohort consisted of 25 patients that received insulin with no particular protocol, and a further 36 using new clinical data from short term (24 hour) and long STAR-NICU trials (Le Compte et al., 2011). This clinical data was derived from extremely low birth weight $(<1.0 \mathrm{~kg})$ and very low birth weight neonates $(<1.5 \mathrm{~kg})$. Cohort summary statistics are in Table 2. Notably, two of these patients started hypoglycaemic $(\mathrm{BG}<2.6 \mathrm{mmol} / \mathrm{L})$

\subsection{Analyses and Performance Metrics}

Results were compared against to the existing protocol. The following performance metrics were used:

- SAFETY: number of severe hypoglycaemic events $(\mathrm{BG}<2.6 \mathrm{mmol} / \mathrm{L})$, and hypoglycaemia $(\% \mathrm{BG}<4.0$ $\mathrm{mmol} / \mathrm{L}$ and $\% \mathrm{BG}<3.0 \mathrm{mmol} / \mathrm{L}$ ).

- PERFORMANCE: \%BG within the 4.0-8.0 mmol/L band, and hyperglycaemia ( $\mathrm{BG}>10.0 \mathrm{mmol} / \mathrm{L}$ ).

\section{RESULTS}

\subsection{Control Protocol Results}

Table 3 summarises the results for all 5 protocols. Performance metrics showed that Protocol 1 was the optimum, balancing desired reductions in hyperglycaemia with reduced hypoglycaemic events. Protocol 2 was the most aggressive by design, and thus had significant

Table 2: Clinical patient summary statistics.

\begin{tabular}{|c|c|c|c|c|c|c|c|c|c|c|c|c|}
\hline \multirow{2}{*}{ r. } & \multicolumn{4}{|c|}{ Short-term $(\mathrm{N}=8)$} & \multicolumn{4}{|c|}{ Long-term $(\mathrm{N}=28)$} & \multicolumn{4}{|c|}{ Retrospective $(\mathrm{N}=25)$} \\
\hline & Median & {$[\mathrm{IQR}]$} & & & Median & [IQR] & & & Median & [IQR] & & \\
\hline Gestational age at birth (weeks) & 25.6 & {$[24.9$} & - & $26.4]$ & {$[25.4$} & {$[25.0$} & & $26.8]$ & 26.6 & {$[25.4$} & - & $27.7]$ \\
\hline Weight at birth (grams) & 745 & {$[681$} & - & 814] & 760 & {$[601$} & & 925] & 845 & {$[800$} & - & 904] \\
\hline Age at start of trial (days) & 6.6 & {$[3.6$} & - & 7.7] & 3.6 & {$[1.5$} & - & $6.4]$ & $\mathrm{n} / \mathrm{a}$ & & & \\
\hline
\end{tabular}

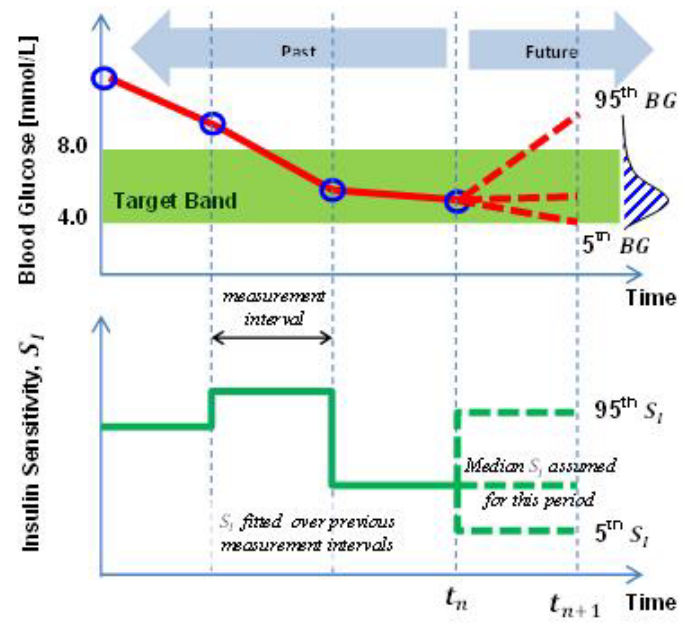

Figure 1: Adaptive control methodology. Distributions of $\boldsymbol{S}_{I}\left(\boldsymbol{t}_{n+1}\right)$ and resulting BG forecast are illustrated

hypoglycaemia. Protocols 3-5 showed little gain maximising certainty, and require more clinical effort.

Figure 2 shows the cumulative distributions for each protocol. The relatively small differences between protocols is attributed to high inter- and intra- patient variability, dominating the ability to control BG.

\subsection{Sensitivity Analysis on Protocol 1}

Figure 3 presents the sensitivity analysis on the limit on the increase in insulin. As larger changes in insulin were permitted, improved time in band was possible, but the incidence of severe hypoglycaemia was increased. Thus, increasing the limit increased hypoglycaemia without significantly decreasing hyperglycaemia.

Table 4 presents results from determining the allowable increase in insulin with BG level and indicates that setting insulin change limits based on current BG levels is effectiveLimiting the increase in insulin rate to $0.015 \mathrm{U} / \mathrm{kg} / \mathrm{hr}$ for $\mathrm{BG}<$ $6 \mathrm{mmol} / \mathrm{L}$, to $0.03 \mathrm{U} / \mathrm{kg} / \mathrm{hr}$ for $6.0 \leq \mathrm{BG} \leq 10 \mathrm{mmol} / \mathrm{L}$, and to $0.06 \mathrm{U} / \mathrm{kg} / \mathrm{hr}$ for $\mathrm{BG}>10 \mathrm{mmol} / \mathrm{L}$ provides the best combination to improve performance and safety.

\subsection{Final Protocol}

The analysis resulted in the development of a final controller defined:

- Stochastic Targeting to place the lower 5th percentile of BG predictions on the lower band limit of $4.0 \mathrm{mmol} / \mathrm{L}$.

- Blood glucose level determined limits on the increase in
Age at start of trial (days) 
insulin between treatments: if $\mathrm{BG}<6.0 \mathrm{mmol} / \mathrm{L}$ the insulin limit is $0.015 \mathrm{U} / \mathrm{kg} / \mathrm{hr}$; if $6.0<\mathrm{BG}<10 \mathrm{mmol} / \mathrm{L}$ the limit is $0.03 \mathrm{U} / \mathrm{kg} / \mathrm{hr}$; if $\mathrm{BG}>10 \mathrm{mmol} / \mathrm{L}$ the limit is $0.06 \mathrm{U} / \mathrm{kg} / \mathrm{hr}$.

- As a safety precaution, for BG $<4.0 \mathrm{mmol} / \mathrm{L}$ no insulin therapy is given.

The final protocol results are presented in Table 5 for the 36 STAR-NICU patients in comparison to clinical results using the previous generation controller. Virtual trials with 3 hour measurement intervals and the clinical measurement intervals are also shown. The new STAR-NICU protocol reduces hypoglycaemia and $\% \mathrm{BG}<4.0$, with slightly improved performance.

It is important to note that the clinical data averages 3 hourly measurement with significant variability between patients. Hence, the 3 hourly results are a better direct comparison to clinical data. These results show a $7 \%$ improvement in performance, and a 50\% reduction in hypoglycaemic patients.

\section{DISCUSSION}

Virtual trials to develop a STAR protocol for use in the NICU improves on performance of the current STAR-NICU protocol, which has a very different balance of safety and performance in its design. This new protocol uses stochastic targeting to place the 5 th percentile of predicted BG outcomes on a lower limit of $4.0 \mathrm{mmol} / \mathrm{L}$ to maximize overlap between the range of possible BG outcomes and a clinically specified target band $(4.0-8.0 \mathrm{mmol} / \mathrm{L})$. The maximum increase in insulin is limited based on BG level, so that as the risk of hypoglycaemia decreases, more aggressive insulin treatments can be utilised. This approach allows direct management, of hyper- and hypo- glycaemic risk.

Table 5 shows that, for comparable measurement interval, the new protocol has a $7 \%$ improvement in time in band and lowered incidence of hypoglycaemia. This improvement is relatively small, a fact attributed to limitations caused by high inter- and intra- patient variability. Due to the large bandwidth of forecasted outcomes observed, it is evident that the existing controller also puts the 5th percentile BG on 4.0 $\mathrm{mmol} / \mathrm{L}$ most of the time, despite initially targeting the 50th percentile BG to $6.0 \mathrm{mmol} / \mathrm{L}$. The result is that the control protocols are effectively more similar than they are by

Table 3: Protocol comparison whole cohort re-sampled statistics

\begin{tabular}{|c|c|c|c|c|c|}
\hline & Protocol 1 & Protocol 2 & Protocol 3 & Protocol 4 & Protocol 5 \\
\hline \multicolumn{6}{|l|}{ Performance: } \\
\hline Median BG [IQR] & $\begin{array}{c}6.59 \\
{[5.52-8.55]}\end{array}$ & $\begin{array}{c}5.56 \\
{[4.54-7.40]}\end{array}$ & $\begin{array}{c}6.26 \\
{[5.33-8.00]}\end{array}$ & $\begin{array}{c}6.50 \\
{[5.46-8.25]}\end{array}$ & $\begin{array}{c}6.65 \\
{[5.56-8.61]}\end{array}$ \\
\hline \% BG within $4.0-7.0 \mathrm{mmol} / \mathrm{L}$ & 54.7 & 58.6 & 60.0 & 56.6 & 53.4 \\
\hline \% BG within $4.0-8.0 \mathrm{mmol} / \mathrm{L}$ & 67.2 & 67.0 & 72.2 & 69.6 & 66.4 \\
\hline$\% \mathrm{BG}>10 \mathrm{mmol} / \mathrm{L}$ & 15.9 & 10.2 & 13.0 & 13.9 & 16.6 \\
\hline \multicolumn{6}{|l|}{ Safety: } \\
\hline$\% \mathrm{BG}<4.0 \mathrm{mmol} / \mathrm{L}$ & 2.50 & 12.56 & 2.84 & 2.70 & 2.39 \\
\hline$\% \mathrm{BG}<3.0 \mathrm{mmol} / \mathrm{L}$ & 0.39 & 1.97 & 0.42 & 0.60 & 0.39 \\
\hline Num patients* $<2.6 \mathrm{mmol} / \mathrm{L}$ & 5 & 29 & 5 & 8 & 4 \\
\hline $\begin{array}{c}\text { Median Insulin Rate[IQR] } \\
\text { (U/kg/hr) }\end{array}$ & $\begin{array}{c}0.034 \\
{[0.027-0.048]}\end{array}$ & $\begin{array}{c}0.033 \\
{[0.030-0.059]}\end{array}$ & $\begin{array}{c}0.032 \\
{[0.026-0.043]}\end{array}$ & $\begin{array}{c}0.029 \\
{[0.020-0.036]}\end{array}$ & $\begin{array}{c}0.031 \\
{[0.025-0.043]}\end{array}$ \\
\hline $\begin{array}{c}\text { Median Glucose Rate[IQR] } \\
(\mathrm{mg} / \mathrm{kg} / \mathrm{min}):\end{array}$ & $\begin{array}{c}8.0 \\
{[6.1-9.2]}\end{array}$ & $\begin{array}{c}8.0 \\
{[6.1-9.2]}\end{array}$ & $\begin{array}{c}8.0 \\
{[6.1-9.2]}\end{array}$ & $\begin{array}{c}8.0 \\
{[6.1-9.2]}\end{array}$ & $\begin{array}{c}8.0 \\
{[6.1-9.2]}\end{array}$ \\
\hline
\end{tabular}

* Not including the one patient that started low, but did not have subsequent $\mathrm{BG}<2.6 \mathrm{mmol} / \mathrm{L}$

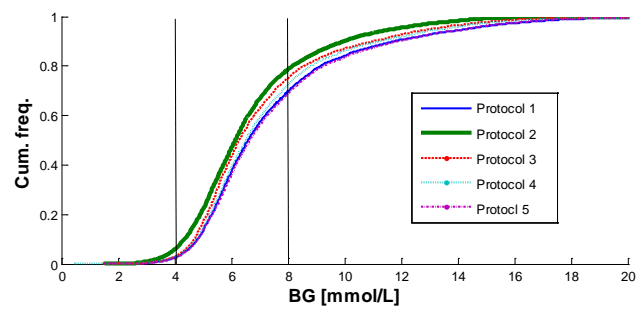

Figure 2: BG cumulative distribution across entire cohort The desired $4.0-8.0 \mathrm{mmol} / \mathrm{L}$ band is outlined showing performance and safety bounds
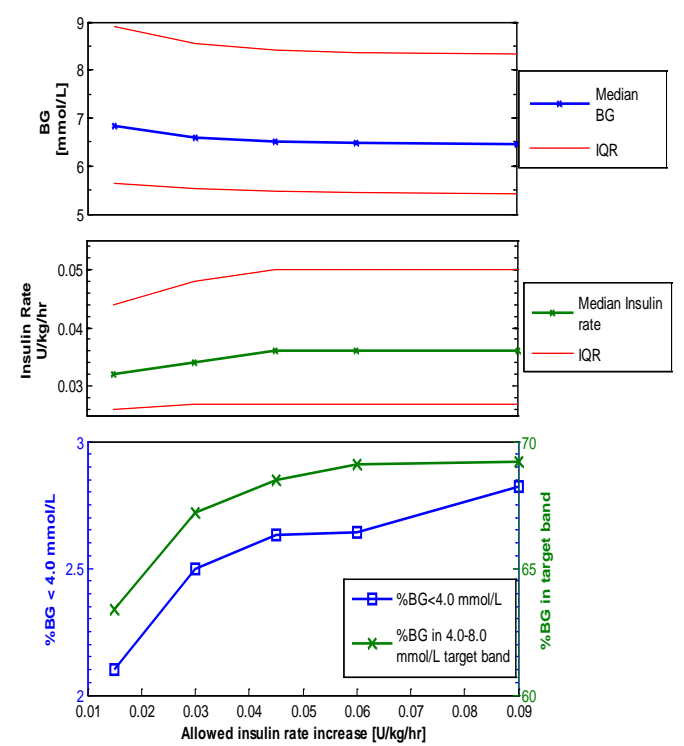

Figure 3: Sensitivity analysis on insulin increase limit, showing impact on the primary performance and safety. 
Table 4:BG defined limits on insulin (U/kg/hr)

\begin{tabular}{|c|c|c|c|c|c|}
\hline & $\begin{array}{c}\text { For BG }<6 \text { limit } \\
0.015 \mathrm{U} / \mathrm{kg} / \mathrm{hr} \text {, } \\
\text { else } 0.03 \mathrm{U} / \mathrm{kg} / \mathrm{hr}\end{array}$ & $\begin{array}{c}\text { For } \\
\text { BG }<\text { 7limit } \\
0.015 \mathrm{U} / \mathrm{kg} / \mathrm{hr} \text {, } \\
\text { else } 0.03 \\
\text { U/kg/hr } \\
\end{array}$ & $\begin{array}{c}\text { For BG }<7 \text { limit } 0.015 \\
\text { U/kg/hr, else if } \\
\text { BG }>10 \text { limit } 0.06 \\
\text { U/kg/hr, else } 0.03 \\
\text { U/kg/hr }\end{array}$ & $\begin{array}{c}\text { For BG<6 limit } \\
0.015 \mathrm{U} / \mathrm{kg} / \mathrm{hr} \text {, else } \\
\text { if } B G>9 \text { limit } 0.06 \\
\mathrm{U} / \mathrm{kg} / \mathrm{hr}, \text { else } 0.03 \\
\mathrm{U} / \mathrm{kg} / \mathrm{hr} \\
\end{array}$ & $\begin{array}{c}\text { For BG }<6 \text { limit } \\
0.015 \mathrm{U} / \mathrm{kg} / \mathrm{hr} \text {, else if } \\
\text { BG }>10 \text { limit } 0.06 \\
\mathrm{U} / \mathrm{kg} / \mathrm{hr}, \text { else } 0.03 \\
\mathrm{U} / \mathrm{kg} / \mathrm{hr} \\
\end{array}$ \\
\hline \multicolumn{6}{|l|}{ Performance: } \\
\hline Median BG [IQR] & $\begin{array}{c}6.60 \\
{[5.52-8.55]}\end{array}$ & $\begin{array}{c}6.60 \\
{[5.52-8.55]}\end{array}$ & $\begin{array}{c}6.61 \\
{[5.55-8.46]}\end{array}$ & $\begin{array}{c}6.55 \\
{[5.51-8.42]}\end{array}$ & $\begin{array}{c}6.57 \\
{[5.52-8.43]}\end{array}$ \\
\hline $\begin{array}{c}\% \text { BG within } 4.0-8.0 \\
\mathrm{mmol} / \mathrm{L}\end{array}$ & 67.30 & 67.30 & 67.96 & 68.44 & 68.19 \\
\hline$\% \mathrm{BG}>10 \mathrm{mmol} / \mathrm{L}$ & 15.93 & 15.93 & 15.11 & 14.93 & 15.05 \\
\hline \multicolumn{6}{|l|}{ Safety } \\
\hline$\% \mathrm{BG}<4.0 \mathrm{mmol} / \mathrm{L}$ & 2.32 & 2.32 & 2.25 & 2.45 & 2.38 \\
\hline $\begin{array}{c}\text { Num patients }<2.6 \\
\mathrm{mmol} / \mathrm{L}\end{array}$ & 4 & 4 & 4 & 5 & 4 \\
\hline
\end{tabular}

* Not including the one patient that started low, but did not have subsequent $\mathrm{BG}<2.6 \mathrm{mmol} / \mathrm{L}$

definition. Thus most of the improvement is due to optimisation of targeting parameters, rather than of the control protocol itself.

The effect of patient variability, represented by the width of the $5^{\text {th }}-95^{\text {th }}$ stochastic prediction band, can be seen in Figure 4 . The $5^{\text {th }}$ percentile is almost always on $4.0 \mathrm{mmol} / \mathrm{L}$, as set by the controller, but the $95^{\text {th }}$ percentile can be up to 25 $\mathrm{mmol} / \mathrm{L}$. The model BG curve, as expected, tracks between. This effect is much larger at higher blood glucose levels, where wide prediction bands in $S_{I}$ are magnified by high BG and large recommended insulin dosage. As expected, there are a few incidences where the model BG curve falls below the lower $5^{\text {th }}$ percentile, which has a $5 \%$ chance of occurrence by definition. However, the upper $95^{\text {th }}$ percentile is quite clearly over-conservative, and does not display the expected $5 \%$ occurrence of BG above this level. These results indicate a need for refinement of the stochastic models.

Through the use of limits on the maximum change in insulin rate, some of the benefits in performance of other protocols were realised in Protocol 1. As seen in Figure 3, beyond the limit on the increase of insulin to around $0.045 \mathrm{U} / \mathrm{kg} / \mathrm{hr}$, the

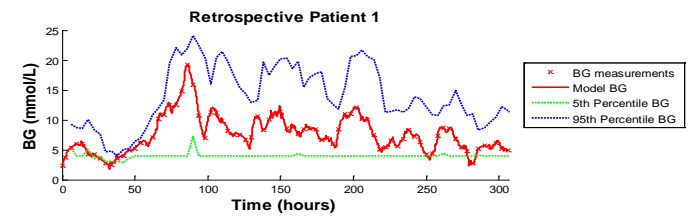

Figure 4: BG response over time with simulated forecast bands for a representative patient.

difference between median insulin rate and time in band statistics is much lower than that for limits between 0.015 to $0.045 \mathrm{U} / \mathrm{kg} / \mathrm{hr}$. This result suggests that the use of limits below $0.045 \mathrm{U} / \mathrm{kg} / \mathrm{hr}$ moderates any hypoglycaemia due to sudden rises in $S_{I}$ Thus, BG dependeant limits on the increase in the insulin rate are effective at balancing aggressive and safe control.

An overall and significant outcome was a better understanding of the limitations of current models and the significant effect of patient variability on control performance for this cohort. Although some improvement in performance was achieved, they are unlikely to be clinically substantial.

Table 5: Comparison of Optimized Controller with Existing NICU Controller

\begin{tabular}{|c|c|c|c|c|}
\hline & $\begin{array}{l}\text { NICU STAR } \\
\text { Clinical Data }\end{array}$ & $\begin{array}{c}\text { Opti-STAR - } 4 \\
\text { hours (simulated) }\end{array}$ & $\begin{array}{c}\text { Opti-STAR - } 3 \\
\text { hours (simulated) }\end{array}$ & $\begin{array}{c}\text { Opti-STAR - clinical } \\
\text { measurement } \\
\text { interval }\end{array}$ \\
\hline \multicolumn{5}{|l|}{ Clinical Effort: } \\
\hline Measurements/day [IQR] & $8.1[7.2-9.6]$ & $6.7[6.3-6.9]$ & $8.5[8.2-8.8]$ & $8.1[7.2-9.6]$ \\
\hline \multicolumn{5}{|l|}{ Performance: } \\
\hline $\begin{array}{c}\text { Median BG [IQR] } \\
\% \text { BG within } 4.0-8.0 \mathrm{mmol} / \mathrm{L}\end{array}$ & $\begin{array}{c}6.6[5.5-8.2] \\
68.48\end{array}$ & $\begin{array}{c}6.57[5.52-8.41] \\
67.6\end{array}$ & $\begin{array}{c}6.3[5.31-8.09] \\
72.1\end{array}$ & $\begin{array}{c}6.59[5.45-8.53] \\
67.5\end{array}$ \\
\hline$\% \mathrm{BG}>10 \mathrm{mmol} / \mathrm{L}$ & 12.51 & 17.7 & 14.3 & 16.0 \\
\hline \multicolumn{5}{|l|}{ Safety: } \\
\hline$\% \mathrm{BG}<4.0 \mathrm{mmol} / \mathrm{L}$ & 3.67 & 2.19 & 2.1 & 2.54 \\
\hline$\% \mathrm{BG}<3.0 \mathrm{mmol} / \mathrm{L}$ & 0.46 & 0.39 & 0.23 & 0.55 \\
\hline Num patients $<2.6 \mathrm{mmol} / \mathrm{L}$ & 4 & 3 & 2 & 2 \\
\hline $\begin{array}{l}\text { Median Insulin Rate[IQR] } \\
\text { (U/kg/hr) }\end{array}$ & $\begin{array}{c}0.034 \\
{[0.029-0.051]}\end{array}$ & $\begin{array}{c}0.034 \\
{[0.027-0.048]}\end{array}$ & $\begin{array}{c}0.040 \\
{[0.030-0.052]}\end{array}$ & $\begin{array}{c}0.043 \\
{[0.032-0.057]}\end{array}$ \\
\hline $\begin{array}{l}\text { Median Glucose Rate[IQR] } \\
\text { (mg/kg/min): }\end{array}$ & $8.0[6.5-9.3]$ & $8.0[6.1-9.2]$ & $8.0[6.1-9.2]$ & $7.6[5.3-9.3]$ \\
\hline
\end{tabular}


This outcome is attributed to the high level of inter- and intrapatient variability. However, the limitations of such variability on neonatal glycaemic control were still unknown.

Figure 4, shows how control is severely limited by overly conservative bands, the $5^{\text {th }}$ percentile BG forecast is almost always at $4 \mathrm{mmol} / \mathrm{L}$. To achieve greater glycaemic control performance methods must be investigated to better capture patient-specific variation to mitigate this issue.

Further limitations are present in the form of restrictions on the number of blood glucose measurements that can be taken in a set time period. Neonates have extremely limited blood volume, so the lower limit on measurement interval is 2 hours, with clinical preference being 3-4 hours. Hence, the control protocols are optimised for 4 hourly intervals, although 3 hourly intervals gives better performance.

\section{CONCLUSIONS}

The main outcomes from this study were the optimisation of the NICU-STAR controller, and a greater understanding of the limitation of current control methods because of interand intra- patient variability. The control protocol optimised selected the insulin infusion rate that put the 5 th percentile BG prediction on $4.0 \mathrm{mmol} / \mathrm{L}$. In addition, BG dependent limits on the increase in insulin rates was found to be an effective way to lower hyperglycaemia without increasing hypoglycaemia. It was found that the optimised controller outperformed the existing STAR-NICU controller by around $7 \%$ in clinically validated virtual trials using 3 hourly measurement intervals, a result attributed to optimisation of control parameters, rather than specific differences in control methods. To further improve control, better quantification of inter- and intra- patient variability are required, as this variability limits the amount of insulin that can be safely administered, which sets the focus for next steps in this field.

\section{REFERENCES}

ALAEDEEN, D. I., WALSH, M. C. \& CHWALS, W. J. 2006. Total parenteral nutrition-associated hyperglycemia correlates with prolonged mechanical ventilation and hospital stay in septic infants. $J$ Pediatr Surg, 41, 239-44.

BARKER, D. P. \& RUTTER, N. 1996. Stress, severity of illness, and outcome in ventilated preterm infants. Archives of disease in childhood, 75, F187-90.

BEARDSALL, K., VANHAESEBROUCK, S., OGILVYSTUART, A. L., VANHOLE, C., PALMER, C. R., VAN WEISSENBRUCH, M., MIDGLEY, P., THOMPSON, M., THIO, M., CORNETTE, L., OSSUETTA, I., IGLESIAS, I., THEYSKENS, C., DE JONG, M., AHLUWALIA, J. S., DE ZEGHER, F. \& DUNGER, D. B. 2008. Early Insulin Therapy in VeryLow-Birth-Weight Infants. N Engl J Med, 359, 18731884.

BINDER, N. D., RASCHKO, P. K., BENDA, G. I. \& REYNOLDS, J. W. 1989. Insulin infusion with parenteral nutrition in extremely low birth weight infants with hyperglycemia. The Journal of pediatrics, $114,273-80$
CHASE, J. G., SUHAIMI, F., PENNING, S., PREISER, J. C., LE COMPTE, A. J., LIN, J., PRETTY, C. G., SHAW, G. M., MOORHEAD, K. T. \& DESAIVE, T. 2010. Validation of a model-based virtual trials method for tight glycemic control in intensive care. Biomed Eng Online, 9, 84.

COLLINS, J. W., JR., HOPPE, M., BROWN, K., EDIDIN, D. V., PADBURY, J. \& OGATA, E. S. 1991. A controlled trial of insulin infusion and parenteral nutrition in extremely low birth weight infants with glucose intolerance. The Journal of pediatrics, 118, 921-7.

FARRAG, H. M., NAWRATH, L. M., HEALEY, J. E., DORCUS, E. J., RAPOZA, R. E., OH, W. \& COWETT, R. M. 1997. Persistent glucose production and greater peripheral sensitivity to insulin in the neonate vs. the adult. Am J Physiol, 272, E86-93.

HAYS, S. P., SMITH, B. \& SUNEHAG, A. L. 2006. Hyperglycemia Is a Risk Factor for Early Death and Morbidity in Extremely Low Birth-Weight Infants. Pediatrics, 118, 1811-1818.

HEIMANN, K., PESCHGENS, T., KWIECIEN, R., STANZEL, S., HOERNCHEN, H. \& MERZ, U. 2007. Are recurrent hyperglycemic episodes and median blood glucose level a prognostic factor for increased morbidity and mortality in premature infants $</=1500$ g? Journal of perinatal medicine, 35, 245-8.

KANAREK, K. S., SANTEIRO, M. L. \& MALONE, J. I. 1991. Continuous infusion of insulin in hyperglycemic low-birth weight infants receiving parenteral nutrition with and without lipid emulsion. J Parenter Enteral Nutr, 15, 417-20.

LE COMPTE, A., CHASE, J. G., LYNN, A., HANN, C., SHAW, G., WONG, X.-W. \& LIN, J. 2009. Blood Glucose Controller for Neonatal Intensive Care: Virtual Trials Development and First Clinical Trials. Journal of Diabetes Science and Technology, 3, 1066-1081.

LE COMPTE, A., CHASE, J. G., RUSSELL, G., LYNN, A., HANN, C., SHAW, G., WONG, X. W., BLAKEMORE, A. \& LIN, J. 2010a. Modeling the glucose regulatory system in extreme preterm infants. Comput Methods Programs Biomed.

LE COMPTE, A. J., LEE, D. S., CHASE, J. G., LIN, J., LYNN, A. \& SHAW, G. M. 2010b. Blood glucose prediction using stochastic modeling in neonatal intensive care. IEEE Trans Biomed Eng, 57, 509-18.

LE COMPTE, A. J., PRETTY, C. G., LIN, J., SHAW, G. M., LYNN, A. \& CHASE, J. G. 2011. Impact of variation in patient response on model-based control of glycaemia in critically ill patients. Comput Methods Programs Biomed.

LUCAS, A., MORLEY, R. \& COLE, T. J. 1988. Adverse neurodevelopmental outcome of moderate neonatal hypoglycaemia. Br Med J, 297, 1304-1308.

THABET, F., BOURGEOIS, J., GUY, B. \& PUTET, G. 2003. Continuous insulin infusion in hyperglycaemic very-low-birth-weight infants receiving parenteral nutrition. Clin Nutr, 22, 545-7.
Comment [ID2]: Most of this paragraph is presented in the discussion of Fig. 4, so can potentially have some space to spare... 